\title{
ИНФОРМАТИКА
}

\author{
UDC 519.868
}

A. Lozkins, V. M. Bure

\section{SINGLE HUB LOCATION-ALLOCATION PROBLEM UNDER ROBUSTNESS CLUSTERING CONCEPT}

St. Petersburg State University, 7-9, Universitetskaya nab., St. Petersburg, 199034, Russian Federation

This paper presents an algorithm of hub number $p$ robustness estimation using specific simulations in the single allocation hub location problem. The simulation has to model the service demand trends in each origin node to each destination node. This idea is based on the hub network dependence on service demand forecasting, which is modeled by random values from random distribution with parameters reflecting the demand changes. The algorithm includes the mixed integer programming model which describes the hub location-allocation problem with single allocation (each node is connected exactly to one hub). The model chooses the optimal locations for the fixed number of hubs $p$ from the fixed possible location set in the problem. The perturbed data simulate the changes in the service need and present the perspectives of the network changes, and the algorithm fixes these changes. The number of changes in the network is consolidated into the variety frequencies which describe the variabilities in the set of simulations. The algorithm is implemented on Python 3.5 and model optimization is fulfilled using Gurobi Optimizer 7.0.1 software. The results in the real dataset are illustrated and discussed. Refs 18. Fig. 1. Tables 3.

Keywords: hub location-allocation, network stability, cluster number robustness, linear programming.

\section{А. Ложкинс, В. М. Буре}

\section{ЗАДАЧА РАСПОЛОЖЕНИЯ $p$-ХАБОВ В КОНЦЕПЦИИ РОБАСТНОСТИ КЛАСТЕРИЗАЦИИ}

Санкт-Петербургский государственный университет, Российская Федерация, 199034, Санкт-Петербург, Университетская наб., 7-9

В работе представлен подход к оценке робастности сети терминалов и хабов в задаче о размещении узлов консолидации в сети с количеством хабов, равным $p$. Предлагаемый алгоритм основан на многочисленных симуляциях ситуаций спроса на услуги в терминалах. В ходе каждой симуляции в сети генерируется ситуация, отражающая возможный спрос

Lozkins Aleksejs - master of applied mathematics and computer science, postgraduent student; aleksejs.lozkin@gmail.com

Bure Vladimir Mansurovich - doctor of technical sciences, professor; vlb310154@gmail.com

Ложкинс Алексейс - магистр прикладной математики и информатики, аспирант; aleksejs.lozkin@gmail.com

Буре Владимир Мансурович - доктор технических наук, профессор; vlb310154@gmail.com

(C) Санкт-Петербургский государственный университет, 2017 
услуг в каждом терминале. Спрос услуг в каждом терминале - это случайная величина из вероятностного распределения. Вероятностное распределение для каждого терминала выбирается таким образом, чтобы отразить вероятные изменения спроса в будущем. Таким образом, каждая симуляция является предсказанием грузопотока, на основе которого осуществляется выбор хабов в сети. В каждой симуляции решается задача целочисленного программирования, которая описывает задачу размещения хабов в сети терминалов и задачу распределения терминал-хаб. В результате использования модели определяются оптимальные места расположения $p$-хабов из фиксированного множества возможных расположений хабов. Предполагается, что возможные расположения хабов известны и их число превышает $p$. Алгоритм проводит заданное количество симуляций для заданного множества значений $p$. Результат решения задачи целочисленного программирования сравнивается с изначальным решением, полученным без возмущения спроса. Количество изменений сети объединяется в параметр - частоту сменяемости сети, который описывает изменчивость сети в ряде симуляций. В каждой симуляции решается своя задача целочисленного программирования, где спрос или количество хабов $p$ в сети отличается от других. Результат работы алгоритма - это множество значений $p$ с соответствующими значениями частот сменяемости. Наименьшее значение частоты сменяемости для $p$ означает, что в результате многочисленных симуляций число решений с возмущенным спросом для $p$-хабов совпадало с изначальным решением наибольшее количество раз. Алгоритм реализован с использованием языка программирования Python 3.5 , задачи целочисленного программирования были решены в Gurobi Optimizer 7.0.1. Проведен численный эксперимент на реальных данных и приведены его результаты. Библиогр. 18 назв. Ил. 1. Табл. 3.

Ключевые слова: размещение хабов, устойчивость сети, робастность числа кластеров, линейное программирование.

Introduction. We consider a network of hubs in which some commodities are consolidated in the nodes named a hubs from non-hub nodes. The role of the hubs in the network is a specified set of facilities (switching, transshipment, sorting, etc.) for indirect connections between non-hubs via hubs nodes instead of connecting direct links for every origin-destination route. The requirements in hubs facilities arise when some commodities flow must be transported from a set of origins to a set of destinations in cases, when it is too expensive to create a direct non-hub nodes connections or is impossible in general. The hubs location-allocation is discussed as the most important problem in the transport network field. The problem is of how to allocate hubs to produce high performance in the network.

Facility location problems have been widely studied in computer networks, airlines, transportation, postal delivery systems and telecommunications. The hub introduction in this network is aimed to minimize the total costs for the movements of all flows. The goal of our research is to predict robust number of hub in the network and likely optimal hub location based on the spatial location, demand and sorting costs. The demand forecasting contributes the perturbations in the facilities location planning. In this way the most likely steady hub number and locations are preferred.

There are many proposals for solving the fundamental hub location problem, where the hub network is complete, each non-hub node is associated exactly with one hub (so called single hub location-allocation problem). This work relates to the original hub location problem firstly formulated by O'Kelly in [1, 2]: the uncapacitated single allocation $p$-hub median problem (USApHMP). There are many modifications of this issue: the strategic hub location problems are paid attention in the Alamur and Kara [3] and Campbell and O'Kelly [4] works, the continuous hub location problem is considered in [5], where the hub nodes can be allowed to be located anywhere in a region. The fixed discrete set of nodes of possible hub location problem there is presented in [6, 7]. The problem solution depending on the resilience is considered in $[8,9]$. The variation of the hub 
allocation problem is capacitated single allocation $p$-hub median problem (CSApHMP). This field assumes different ways of capacities introduction in the model: capacities on flow into hub or total flow [10], the minimum flow value is needed to allow link between nonhub node and hub [11]. The hub locations problem applications in postal delivery services, emergency services and logistic systems [12-14]. The complex cost function (open/close hub costs, different costs for each link between nodes, costs limitation for the flow between hubs) and multiple hub allocations are presented in [15].

When a network constructed depending on the demand and the reliability of its services offered to customers on the operations of the network robustness are considered in [16]. The difference of the model proposed in [16] and current research is in the robustness object, this work considers the clustering stability under random simulations following the algorithms in $[17,18]$.

Proposed problem. The model described in this paper presents the cluster analysis application in USApHMP. The problem consists of location hubs and allocating nonhub nodes to them. The most stable (in [17, 18] stability understanding) solution of the problem, which tends to minimize cost function is the goal of this research. The cost function includes the hub opening costs, the cost of the links between hubs and non-hub nodes, which depend on the distances and flows.

The fixed discrete set of possible hub locations and fixed set of hubs existing in the network are considered. The connection between hubs is not restricted, the capacity constraints are not introduced in the model.

The demand on the services consists of two parts: fixed demand value (current demand on the service) and demand changes, which are simulated by fixed random distribution. The second part of the demand presents the changes in the demand, which arise the network changeability. Under this uncertainty the network stability is estimated.

The model proposes the stable number of hubs in the network. This is not a classical problem in USApHMP, where the hub number is fixed, that makes something new in the hub allocation-location field.

Mathematical formulation of USAPHMP. The indices, parameters and decision variables used in the model are presented below.

Indicies:

$i$ : Non-hub node of origin;

$j$ : Non-hub node of destination;

$k$ : Hub node (the first distribution);

$l$ : Hub node (the second distribution).

\section{Parameters:}

$a_{i k}$ : Distance from non-hub node $i$ to hub node $k$;

$b_{k l}:$ Distance from hub $k$ to hub $l$;

$d_{l j}$ : Distance from hub $l$ to non-hub $j$;

$c_{i k}$ : Flow cost between hub $k$ and non-hub $i$;

$e_{k l}$ : Flow cost between hub $k$ and hub $l$;

$n_{l j}$ : Flow cost between hub $l$ and non-hub $j$;

$f_{k}$ : Fixed cost of hub constructing $k$;

$w_{i j}$ : Flow demand between non-hub $i$ and non-hub $j$;

$p$ : Hub amount in the network. 
Decision variables:

$x_{i k}$ : The link between hub $k$ and non-hub node $i$;

$z_{k l j}$ : Flow demand between hub $k$ and hub $l$ that comes to non-hub node $j$;

$v_{k}$ : If hub $k$ is selected for allocation 1 , otherwise 0.

Mathematical model. The hub location-allocation mathematical model's formal form is presented below:

$$
\min Z=\sum_{i=1}^{N} \sum_{j=1, j \neq i}^{N} \sum_{k=1}^{K} c_{i k} a_{i k} w_{i j} x_{i k}+\sum_{k=1}^{K} \sum_{l=1}^{K} \sum_{j=1}^{N}\left(e_{k l} b_{k l}+n_{l j} d_{l j}\right) z_{k l j}+\sum_{k=1}^{K} f_{k} v_{k} .
$$

Subject to:

$$
\begin{gathered}
\sum_{i} x_{i k} w_{i j}=\sum_{l} z_{k l j} \quad \forall k=1, \ldots, K, \forall j=1, \ldots, N, \\
z_{k l j} \leqslant M x_{j l} \quad \forall k, l=1, \ldots, K, \forall j=1, \ldots, N, \\
\sum_{k} x_{i k}=1 \quad \forall i=1, \ldots, N, \\
x_{i k} \leqslant v_{k} \quad \forall i=1, \ldots, N, \forall k=1, \ldots, K, \\
\sum_{k=1}^{K} v_{k}=p, \\
z_{k l j} \geqslant 0, \quad v_{k}, x_{j k} \in\{0,1\} \quad \forall k, l=1, \ldots, K, \forall j=1, \ldots, N .
\end{gathered}
$$

Objective function:

(1). In the objective function of the proposed model we seek to minimize the transportation costs from origin to destination and hub opening costs. The transportation costs are the multiplication of the demand, the distance and costs of transport demand. The location and allocation tend to be done in a way to minimize the total distance taking into account the flow costs in the network.

Constraints:

(2). Total flow that is consolidated in the hub $k$ and has a final destination $j$ should be equal to the sum of the flows that are distributed in the second hubs on the same final destination.

(3). If there is a connection between hub $l$ and non-hub $j$ then the flow between this nodes is possible otherwise it is equal to 0 . The constant $M$ is a large number which is greater than maximal possible demand flow in the network.

(4). Each non-hub node is allocated only to one hub, i. e. two hubs connected with one non-hub is an impossible condition.

(5). The connection between non-hub $i$ and hub $k$ is possible if hub $k$ exists, otherwise the connection is not allowed.

(6). The total hub amount (new and old hubs) in the network is fixed and equals to $p$.

(7). Enforce the binary and non-negativity restrictions on the corresponding decision variables.

Algorithm of robustness estimation. In most cases the demand forecasting arises the inaccuracies, the algorithm in this section treats this drawback. The idea is similar 
to $[17,18]$, where the random noises are added to studied dataset for stability level estimation. In this work the perturbations model the changes of the demand by random distribution, the network changes during simulations are fixed and the variability frequency [17] is calculated. The last one is the stability index which is used in the current algorithm.

The additional notation is presented below:

$s$ : Number of the simulations;

$w$ : Initial demand matrix;

$G(W, p)$ : The allocation-location problem described in the section 3 , the $W$ is the demand flow matrix and $p$ number of hubs in the network, where $G(W, p)=\left\{v_{k}\right\}_{k}$;

$F(i, j)$ : The random distribution of flow demand changes from origin $i$ to destination $j$;

$F$ : The matrix of perturbations of demand flows, where $F=\{F(i, j)\}_{(i, j)}$.

The simulations in the algorithm are repeated several times like imitations. Each step result is compared with basic solution for corespondent hub amount equals to $p$. The pattern solution is calculated on the non-noised demand data.

The similarity measure represents the differs between initial problem solution (initial hub set) and perturbed demand flow hub location-allocation solution (perturbed hub set). If both hub sets are equal, to 0 , otherwise to 1 :

$$
d(G(w, p), G(w+F, p))=\left\{\begin{array}{ll}
0, & \text { if } v_{i}=v_{i}^{q} \\
1, & \text { otherwise. }
\end{array} \forall v_{i} \in G(w, p) \text { and } v_{i}^{q} \in G(w+F, p),\right.
$$

The algorithm takes additional parameter $\left[p_{\mathbf{m i n}}, p_{\mathbf{m a x}}\right]$ called the hub number interval. The result is the set of frequencies $\left\{\nu_{p}\right\}_{p \in\left[p_{\min }, p_{\max }\right]}$.

Algorithm of robustness estimation:

Input: $w,\left[p_{\min }, p_{\max }\right], F$;

Output: $\nu_{p}$;

Requires: $G(W, p), d(G(w, p), G(w+F, p))$;

for (Iter Num in 1..NumOfRepetitions) do

Generation of matrix $F_{\text {IterNum; }}$;

$W_{\text {IterNum }}=w+F_{\text {IterNum }}$;

for $p \in\left[p_{\min }, p_{\max }\right]$ do

DifferStatus $_{p}=$ DifferStatus $p+d\left(G(w, p), G\left(W_{\text {IterNum }}, p\right)\right)$;

end for

end for

for $p \in\left[p_{\min }, p_{\max }\right]$ do

$\nu_{p}=\frac{\text { DifferStatus }_{p}}{\text { NumOfRepetitions }}$

end for

Numerical example. The core of the algorithm proposed in the previous section is the mathematical description of hub location-allocation problem. The math programming formulations for each iteration in the algorithm were solved using GUROBI Optimizer 7.0.1 with calculation stoping restriction GAP $<4 \%$. The results were obtained in the macOS Sierra environment with Intel Core i5 2.7GHz processor and 8GB RAM. The hub variety frequencies calculation and flow perturbation were released using PyCharm IDE for Python 3.5. 


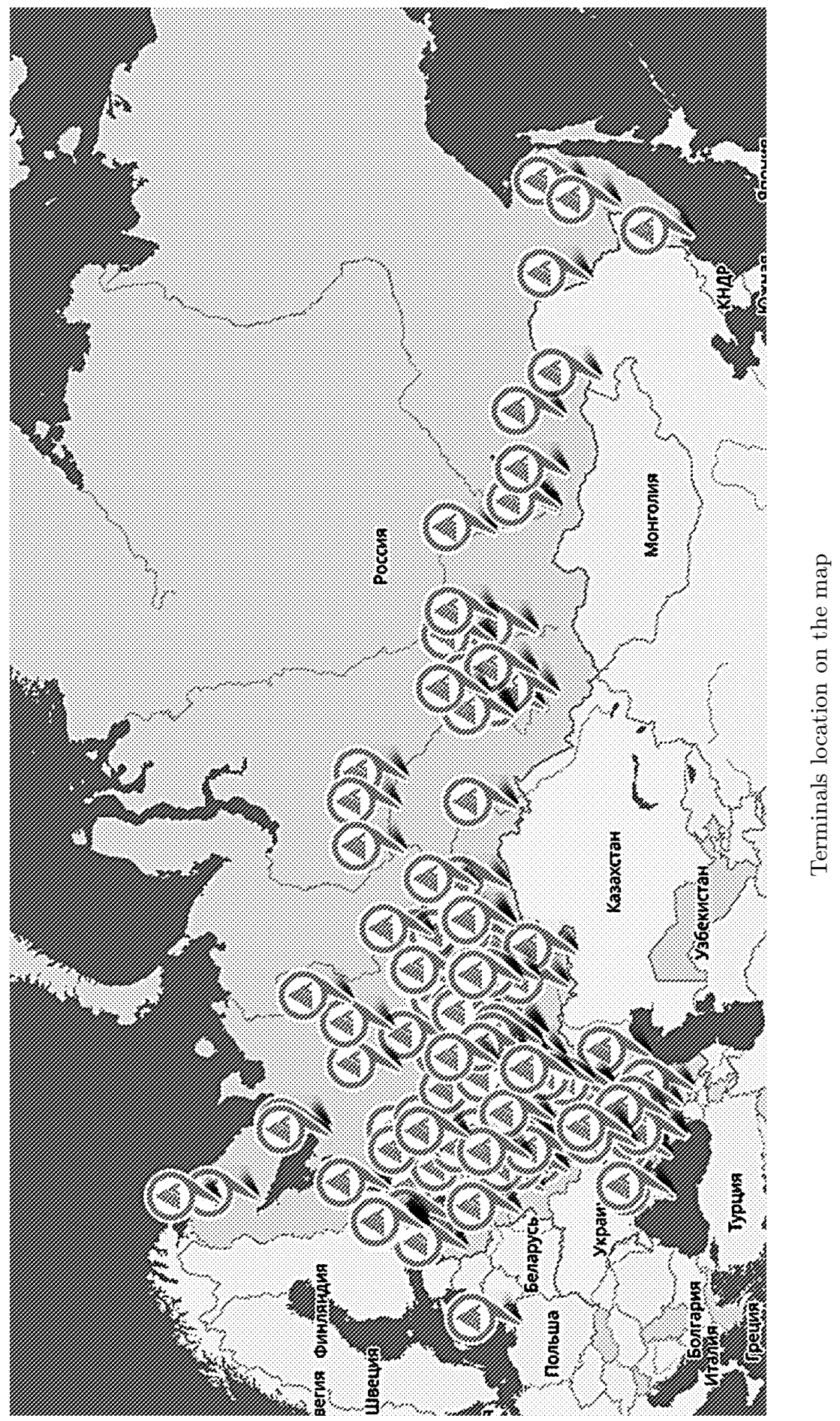


The experiment was carried out on the dataset granted by Company "Delovye linii". The data consist of the set of terminals coordinates (178 terminals, Figure), set of possible hub locations (10 potential hubs), the costs of hub construction and transportation costs depending on the direction. The distances between hubs and terminal-hubs were calculated in seconds (driving time by car without traffic jams consideration) using Google Maps Distance Matrix API (Python Client library).

In this example we have considered the hub quantities from 6 to $9\left(p_{\min }=6, p_{\max }=\right.$ 9 ), the repetitions amount for each hubs quantity in the problem were equal to 10 (in total case there were $4 \cdot(10+1)=44$ simulations), the MIP sizes in each iteration were 19680 variables (17 890 continuous, 1790 binary) and 21539 constraints.

The flows perturbation was generated by Truncated Normal Distribution with mean equal to 30 and standard deviation equal to 80 with same distribution for each direction of flow. The hub construction costs were identical and were equal to 3 million units. This part of data was not granted by company for reasons of confidentiality policy, but the average values and standard deviations were proposed.

The values of the hub location variables $v$ for each considered iteration and hub number in the network $p$ are shown in the column "Hub set" of the Tables 1 and 2. The solving time, GAP and objective function values are shown in the last three columns of the Tables 1 and 2 respectively. The Table 3 contains the information about the resulting variety frequencies and the result of the algorithm application at all.

We have solved the MIP problems using Gurobi during the algorithm implementation, where the objective function values, GAP's and the solving times of the models are obtained. The goal of this experiment has been fulfilled - the variety frequencies were calculated. Following the results in the Table 1, the most stable number of hubs from the considered hub set is 7 hubs.

Table 1. Calculation results for 6 and 7 hub number

\begin{tabular}{|c|c|c|c|c|c|c|}
\hline $\mathrm{N}$ & Hub set & $p$ & Iteration & Time & GAP & Objective \\
\hline 1 & $v_{2}, v_{4}, v_{5}, v_{6}, v_{7}, v_{8}$ & 6 & 0 & 97.70 & $3.91 \%$ & $1.387525677115 \mathrm{e}+10$ \\
\hline 2 & $v_{1}, v_{2}, v_{4}, v_{5}, v_{7}, v_{8}$ & 6 & 1 & 1033.27 & $3.72 \%$ & $1.606515242993 \mathrm{e}+10$ \\
\hline 3 & $v_{1}, v_{2}, v_{5}, v_{6}, v_{7}, v_{8}$ & 6 & 2 & 947.72 & $3.99 \%$ & $1.600605204346 \mathrm{e}+10$ \\
\hline 4 & $v_{2}, v_{4}, v_{5}, v_{6}, v_{7}, v_{8}$ & 6 & 3 & 1085.50 & $3.92 \%$ & $1.589614732368 \mathrm{e}+10$ \\
\hline 5 & $v_{2}, v_{4}, v_{5}, v_{6}, v_{7}, v_{8}$ & 6 & 4 & 602.84 & $2.86 \%$ & $1.603242156357 \mathrm{e}+10$ \\
\hline 6 & $v_{2}, v_{4}, v_{5}, v_{6}, v_{7}, v_{8}$ & 6 & 5 & 251.44 & $3.92 \%$ & $1.601942596109 \mathrm{e}+10$ \\
\hline 7 & $v_{1}, v_{2}, v_{4}, v_{5}, v_{7}, v_{8}$ & 6 & 6 & 700.80 & $3.86 \%$ & $1.603667861850 \mathrm{e}+10$ \\
\hline 8 & $v_{1}, v_{2}, v_{5}, v_{6}, v_{7}, v_{8}$ & 6 & 7 & 940.15 & $3.89 \%$ & $1.598207202599 \mathrm{e}+10$ \\
\hline 9 & $v_{2}, v_{4}, v_{5}, v_{6}, v_{7}, v_{8}$ & 6 & 8 & 286.67 & $3.72 \%$ & $1.595922771159 \mathrm{e}+10$ \\
\hline 10 & $v_{1}, v_{2}, v_{5}, v_{6}, v_{7}, v_{8}$ & 6 & 9 & 688.53 & $3.88 \%$ & $1.614569370209 \mathrm{e}+10$ \\
\hline 11 & $v_{1}, v_{2}, v_{4}, v_{5}, v_{7}, v_{8}$ & 6 & 10 & 840.28 & $3.42 \%$ & $1.593454689837 \mathrm{e}+10$ \\
\hline 12 & $v_{1}, v_{2}, v_{4}, v_{5}, v_{6}, v_{7}, v_{8}$ & 7 & 0 & 25.03 & $3.00 \%$ & $1.359728107390 \mathrm{e}+10$ \\
\hline 13 & $v_{1}, v_{2}, v_{4}, v_{5}, v_{6}, v_{7}, v_{8}$ & 7 & 1 & 15.83 & $3.20 \%$ & $1.550544940590 \mathrm{e}+10$ \\
\hline 14 & $v_{1}, v_{2}, v_{4}, v_{5}, v_{6}, v_{7}, v_{8}$ & 7 & 2 & 18.03 & $3.96 \%$ & $1.562530283109 \mathrm{e}+10$ \\
\hline 15 & $v_{1}, v_{2}, v_{4}, v_{5}, v_{6}, v_{7}, v_{8}$ & 7 & 3 & 19.55 & $2.83 \%$ & $1.541650190022 \mathrm{e}+10$ \\
\hline 16 & $v_{1}, v_{2}, v_{4}, v_{5}, v_{6}, v_{7}, v_{8}$ & 7 & 4 & 16.05 & $3.59 \%$ & $1.560000776191 \mathrm{e}+10$ \\
\hline 17 & $v_{1}, v_{2}, v_{4}, v_{5}, v_{6}, v_{7}, v_{8}$ & 7 & 5 & 16.31 & $3.97 \%$ & $1.560466658456 \mathrm{e}+10$ \\
\hline 18 & $v_{1}, v_{2}, v_{4}, v_{5}, v_{6}, v_{7}, v_{8}$ & 7 & 6 & 26.20 & $3.27 \%$ & $1.548396506806 \mathrm{e}+10$ \\
\hline 19 & $v_{1}, v_{2}, v_{4}, v_{5}, v_{6}, v_{7}, v_{8}$ & 7 & 7 & 15.85 & $3.92 \%$ & $1.557777785333 \mathrm{e}+10$ \\
\hline 20 & $v_{1}, v_{2}, v_{4}, v_{5}, v_{6}, v_{7}, v_{8}$ & 7 & 8 & 21.09 & $3.39 \%$ & $1.550364695775 \mathrm{e}+10$ \\
\hline 21 & $v_{1}, v_{2}, v_{4}, v_{5}, v_{6}, v_{7}, v_{8}$ & 7 & 9 & 32.24 & $3.45 \%$ & $1.554398022930 \mathrm{e}+10$ \\
\hline 22 & $v_{1}, v_{2}, v_{4}, v_{5}, v_{6}, v_{7}, v_{8}$ & 7 & 10 & 50.18 & $3.83 \%$ & $1.564748252323 \mathrm{e}+10$ \\
\hline
\end{tabular}


Table 2. Calculation results for 8 and 9 hub number

\begin{tabular}{|c|c|c|c|c|c|c|}
\hline $\mathrm{N}$ & Hub set & $p$ & Iteration & Time & GAP & Objective \\
\hline 23 & $v_{1}, v_{2}, v_{4}, v_{5}, v_{6}, v_{7}, v_{8}, v_{10}$ & 8 & 0 & 18.93 & $3.71 \%$ & $1.363434591573 \mathrm{e}+10$ \\
\hline 24 & $v_{1}, v_{2}, v_{3}, v_{4}, v_{5}, v_{6}, v_{7}, v_{8}$ & 8 & 1 & 20.52 & $3.69 \%$ & $1.556139694016 \mathrm{e}+10$ \\
\hline 25 & $v_{1}, v_{2}, v_{4}, v_{5}, v_{6}, v_{7}, v_{8}, v_{10}$ & 8 & 2 & 16.88 & $3.20 \%$ & $1.543428870405 \mathrm{e}+10$ \\
\hline 26 & $v_{1}, v_{2}, v_{4}, v_{5}, v_{6}, v_{7}, v_{8}, v_{10}$ & 8 & 3 & 16.08 & $2.83 \%$ & $1.544379866468 \mathrm{e}+10$ \\
\hline 27 & $v_{1}, v_{2}, v_{3}, v_{4}, v_{5}, v_{6}, v_{7}, v_{8}$ & 8 & 4 & 41.18 & $3.74 \%$ & $1.562215298448 \mathrm{e}+10$ \\
\hline 28 & $v_{1}, v_{2}, v_{4}, v_{5}, v_{6}, v_{7}, v_{8}, v_{10}$ & 8 & 5 & 21.92 & $3.82 \%$ & $1.554817063800 \mathrm{e}+10$ \\
\hline 29 & $v_{1}, v_{2}, v_{4}, v_{5}, v_{6}, v_{7}, v_{8}, v_{10}$ & 8 & 6 & 21.39 & $3.01 \%$ & $1.538063403573 \mathrm{e}+10$ \\
\hline 30 & $v_{1}, v_{2}, v_{4}, v_{5}, v_{6}, v_{7}, v_{8}, v_{10}$ & 8 & 7 & 21.49 & $3.95 \%$ & $1.555842742696 \mathrm{e}+10$ \\
\hline 31 & $v_{1}, v_{2}, v_{4}, v_{5}, v_{6}, v_{7}, v_{8}, v_{10}$ & 8 & 8 & 26.74 & $3.10 \%$ & $1.542455334547 \mathrm{e}+10$ \\
\hline 32 & $v_{1}, v_{2}, v_{3}, v_{4}, v_{5}, v_{6}, v_{7}, v_{8}$ & 8 & 9 & 37.83 & $3.22 \%$ & $1.546762118197 \mathrm{e}+10$ \\
\hline 33 & $v_{1}, v_{2}, v_{3}, v_{4}, v_{5}, v_{6}, v_{7}, v_{8}$ & 8 & 10 & 73.51 & $3.57 \%$ & $1.557419468612 \mathrm{e}+10$ \\
\hline 34 & $v_{1}, v_{2}, v_{4}, v_{5}, v_{6}, v_{7}, v_{8}, v_{9}, v_{10}$ & 9 & 0 & 13.92 & $3.98 \%$ & $1.363005615855 \mathrm{e}+10$ \\
\hline 35 & $v_{1}, v_{2}, v_{3}, v_{4}, v_{5}, v_{6}, v_{7}, v_{8}, v_{9}$ & 9 & 1 & 20.75 & $3.09 \%$ & $1.545492616956 \mathrm{e}+10$ \\
\hline 36 & $v_{1}, v_{2}, v_{4}, v_{5}, v_{6}, v_{7}, v_{8}, v_{9}, v_{10}$ & 9 & 2 & 16.88 & $2.51 \%$ & $6380 e+10$ \\
\hline 37 & $v_{1}, v_{2}, v_{3}, v_{4}, v_{5}, v_{6}, v_{7}, v_{8}, v_{9}$ & 9 & 3 & 16.29 & $3.87 \%$ & $1.549357180064 \mathrm{e}+10$ \\
\hline 38 & $v_{1}, v_{2}, v_{3}, v_{4}, v_{5}, v_{6}, v_{7}, v_{8}, v_{10}$ & 9 & 4 & 17.26 & $3.98 \%$ & $1.560257895344 \mathrm{e}+10$ \\
\hline 39 & $v_{1}, v_{2}, v_{3}, v_{4}, v_{5}, v_{6}, v_{7}, v_{8}, v_{10}$ & 9 & 5 & 11.31 & $3.54 \%$ & $1.539155564342 \mathrm{e}+10$ \\
\hline 40 & $v_{1}, v_{2}, v_{3}, v_{4}, v_{5}, v_{6}, v_{7}, v_{8}, v_{10}$ & 9 & 6 & 17.03 & $1.63 \%$ & $1.512499580667 \mathrm{e}+10$ \\
\hline 41 & $v_{1}, v_{2}, v_{3}, v_{4}, v_{5}, v_{6}, v_{7}, v_{8}, v_{10}$ & 9 & 7 & 17.34 & $3.38 \%$ & $1.542159086926 \mathrm{e}+10$ \\
\hline 42 & $v_{1}, v_{2}, v_{4}, v_{5}, v_{6}, v_{7}, v_{8}, v_{9}, v_{10}$ & 9 & 8 & 21.64 & $3.60 \%$ & $1.547391332816 \mathrm{e}+10$ \\
\hline 43 & $v_{1}, v_{2}, v_{3}, v_{4}, v_{5}, v_{6}, v_{7}, v_{8}, v_{10}$ & 9 & 9 & 29.24 & $3.74 \%$ & $1.553031464139 \mathrm{e}+10$ \\
\hline 44 & $v_{1}, v_{2}, v_{3}, v_{4}, v_{5}, v_{6}, v_{7}, v_{8}, v_{10}$ & 9 & 10 & 66.62 & $3.60 \%$ & $1.555782491813 \mathrm{e}+10$ \\
\hline
\end{tabular}

Table 3. Variety frequencies for each hub number

\begin{tabular}{|c|c|c|c|c|}
\hline$p$ & 6 & 7 & 8 & 9 \\
\hline$\nu$ & 0.6 & 0.0 & 0.4 & 0.2 \\
\hline
\end{tabular}

Conclusion. We have presented an idea of hub amount estimation in the network under a model of location-allocation hub covering problem considering the stability concept application in the network constructing. We propose the computationally complex solution for analysing the robustness of the selected number of the hubs in the transportation network. The algorithm described in this paper identifies the competitive hub locations based on the service demand flow perturbations (forecasting). In other words, the results of the proposed approach estimates a proximity of the hubs under demand flow, in cases when the result hub sets differ for the same hub number. We have explored the algorithm application on the real case of data, in general, where simulated 44 mixed integer models and solved that using GUROBI Optimizer 7.0.1 software.

The authors thank Company "Delovye linii" for providing the data for the numerical experiment and discussing results.

\section{References}

1. O'Kelly M. E. Activity levels at hub facilities in interacting networks. Geogr. Anal., 1986, vol. 18(4), pp. 343-356.

2. O'Kelly M. E. The location of interacting hub facilities. Transp. Sci., 1986, vol. 20, pp. 92-105.

3. Alumur S., Kara B. Y. Network hub location problems: the state of the art. European Journal of Oper. Research, 2008, vol. 190, pp. 1-21.

4. Campbell J. F., O'Kelly M. E. Twenty-five years of hub location research. Transp. Sci., 2012, vol. 46(2), pp. 153-169.

5. O'Kelly M. E., Miller H. J. Solution strategies for the single facility minimax hub location problem. Papers in Regional Science, 1991, vol. 70(4), pp. 367-380. 
6. Klincewicz J. G. Heuristics for the p-hub location problem. European Journal of Oper. Research, 1991, vol. 53, pp. 25-37.

7. Skorin-Kapov D., Skorin-Kapov J., O'Kelly M. E. Tight linear programming relaxations of uncapacitated p-hub median problems. European Journal of Oper. Research, 1996, vol. 94, pp. 582-593.

8. Kim H., O'Kelly M. E. Reliable $p$-hub location problems in telecommunication networks. Geogr. Anal., 2009, vol. 41(3), pp. 283-306.

9. O'Kelly M. E. Network hub structure and resilience. Netw. Spat. Econ., 2015, vol. 15(2), pp. $235-251$.

10. Ebery J., Krishnamoorthy M., Ernst A. T., Boland N. The capacitated multiple allocation hub location problems: formulations and algorithms. European Journal of Oper. Research, 2000, vol. 120, pp. 614-631.

11. Lee H., Shi Y., Nazem S. M., Kang S. Y., Park T. H., Sohn M. H. Multicriteria hub decision making for rural area telecommunication networks. European Journal of Oper. Research, 2001, vol. 133, pp. $483-495$.

12. Campbell J. F. Integer programming formulations of discrete hub location problems. European Journal of Oper. Research, 1994, vol. 72, pp. 387-405.

13. Campbell J. F., Ernst A. T., Krishnamoorthy M. Hub location problems. Facility location: applications and theory. Eds by Z. Drezner, H. Hamacher. Berlin, Springer Press, 2002, pp. 373-406.

14. Campbell J. F. Location and allocation for distribution systems with transshipments and transportation economies of scale. Annals of Oper. Research, 1992, vol. 40, pp. 77-99.

15. Fazlollahtabar H. Capacitated location-allocation hub covering problem in manufacturingcustomer interaction. Journal of Appl. Comput. Math., 2015, vol. 4, pp. 243-245. DOI: 10.4172/21689679.1000243

16. Lordan O., Sallan J. M., Simo P., Gonzalez-Prieto D. Robustness of airline alliance route networks. Communications in Nonlinear Science and Numerical Simulation, 2015, vol. 22, no. 1, pp. 587-595.

17. Lozkins A., Bure V. M. The probabilistic method of finding the local-optimum of clustering. Vestnik of Saint Petersburg University. Series 10. Applied Mathematics. Computer Science. Control Processes, 2016, iss. 1, pp. 28-37.

18. Lozkins A., Bure V. M. The method of clusters stability assessing. Stability and Control Processes in memory of V. I. Zubov (SCP). 2015 Intern. Conference. IEEE, 2015, pp. 479-482.

For citation: Lozkins A., Bure V. M. Single hub location-allocation problem under robustness clustering concept. Vestnik of Saint Petersburg University. Applied Mathematics. Computer Science. Control Processes, 2017, vol. 13, iss. 4, pp. 398-406. https://doi.org/10.21638/11701/spbu10.2017.406

Статья рекомендована к печати проф. Л. А. Петросяном.

Статья поступила в редакцию 23 августа 2017 г.

Статья принята к печати 12 октября 2017 г. 